\title{
¿DE QUÉ NACIÓN SON? RESPUESTAS IMPOSIBLES DE TESTIGOS INDÍGENAS EN LOS TIEMPOS INICIALES DE LA COLONIZACIÓN DE CHARCAS
}

\author{
¿DE QUÉ NACIÓN SON? IMPOSSIBLE ANSWERS FROM INDIGENOUS \\ WITNESSES IN CHARCAS' COLONIZATION EARLY TIMES
}

\author{
Lía Guillermina Oliveto*
}

\begin{abstract}
Presentamos un proceso judicial que discurrió a lo largo de la segunda mitad del siglo XVI, iniciado en el Virreinato del Perú y que, dos décadas más tarde, recaló en el Consejo de Indias. En el juicio dos españoles vecinos de la ciudad de La Plata (hoy Sucre, Bolivia) litigaron acerca de quién tenía derecho a incorporar en su encomienda a ciertas autoridades indígenas y sus sujetos. La causa incorpora testimonios indígenas, de españoles y otros elementos de prueba. Indagamos particularmente en las intervenciones de los testigos indígenas, tema historiográficamente desatendido y, sobre todo, en un juicio civil entre españoles en el contexto inicial del afianzamiento de la dominación colonial en el sur andino y de la conformación institucional de la justicia local. Reflexionamos acerca de las posibilidades y limitaciones en la interpretación de la voz indígena en primera persona. También analizamos el centro de la disputa que se ventilaba: la definición de la adscripción étnica de indígenas. Trascendiendo la intención de utilizar el juicio en la búsqueda de la clasificación correcta de los indígenas, proponemos interpretarlas como parte de la disputa entre los encomenderos en la que, por lo menos algunos indígenas, pudieron haber jugado un papel activo.
\end{abstract}

Palabras claves: Testigos indígenas, clasificación étnica, Perú, siglo XVI.

This paper deal with a trial that was sustained in the second half of the 16th Century between two encomenderos. It was initiated in the viceroyalty of Peru and two decades later arrived at the Consejo de Indias. In this lawsuit, two Spaniards from the city of La Plata (now Sucre) litigated about who had the right over two indigenous authorities and their subordinated people. Among other evidence, indigenous witnesses were presented by both contenders. We analyze the testimonies of the indigenous witnesses in the judicial process, a little explored issue by the American Colonial History. It is particularly interesting because the trial took place in the context of the beginning of the institutionalization of local justice and colonial domination. At the same time we reflect on the possibilities and limitations of interpreting the indigenous voice in the first person. We have the opportunity to listen to the definition of their ethnicity but this is an issue that needs to be problematized and revealed. Beyond the interest of searching for the correct classification of indigenous people, we interpret the categories as part of the dispute between the encomenderos in which context, at least some indigenous people, may have played an active role to get the best position.

Key words: Indigenous witnesses, ethnic classifications, Peru, Sixteenth Century.

\section{Introducción}

Un pleito desarrollado entre 1549 y 1572 entre los encomenderos Cristóbal Barba y Juan Ortiz de Zárate, vecinos de la ciudad de La Plata (hoy Sucre, Bolivia), por un conjunto de encomendados permite indagar acerca de los testigos indígenas llamados a declarar de oficio y como parte de las pruebas presentadas por ambos contendientes ${ }^{1}$. Es importante destacar que contamos con la información referente a todas las instancias que atravesó el juicio hasta su sentencia definitiva, luego de la última apelación ante el Consejo de Indias. El expediente del juicio incluye documentación como cédulas de encomiendas (algunas de estas solo se conocen por los traslados incorporados en este juicio), sus tomas de posesión y probanzas presentadas por las partes. Además aparecen como testigos distintos conquistadores y primeros vecinos de la naciente sociedad charqueña, situación verdaderamente singular $^{2}$. En el mismo sentido, las presentaciones de los contendientes, y en particular las declaraciones de los testigos, contienen muy valiosas menciones a las dinámicas y prácticas características de los momentos de la creación de un nuevo mundo colonial, que infrecuentemente hallamos descriptas en la documentación.

\footnotetext{
* Consejo Nacional de Investigaciones Científicas y Técnicas (CONICET). Programa de Historia de América Latina (PROHAL). Instituto de Historia Argentina y Americana “Dr. E. Ravignani”, Facultad de Filosofía y Letras, Universidad de Buenos Aires. Buenos Aires, Argentina. Correo electrónico: goliveto@ conicet.gov.ar
} 
Para contextualizar la disputa presentamos breves consideraciones de los litigantes y el proceso. Juan Ortiz de Zárate fue capitán de caballería, rico empresario colonial e influyente vecino de La Plata, donde sirvió como regidor del cabildo (Presta 2000). Como parte de una red de parientes bien posicionados, tuvo haciendas, casas y negocios en esa ciudad y en Potosí, donde desplegó una variada gama de emprendimientos aprovechando las oportunidades mercantiles que se ofrecían a los encomenderos y propietarios de minas en el Cerro Rico y Porco, tal como lo eran Ortiz de Zárate y su parentela. En 1548, el presidente de la Audiencia de Lima y designado gobernador del Perú, licenciado Pedro de la Gasca, le encomendó los indígenas que en 1540 Francisco Pizarro había otorgado a Francisco Retamoso, los mismos que anteriormente había tenido en encomienda Alonso de Camargo. El repartimiento en cuestión era el de los carangas de Totora y Lípez en el altiplano y sus asentamientos periféricos en los valles orientales de Tarija donde también se le encomendaron a Ortiz de Zárate juríes, chichas y tomatas (Presta 2000; Oliveto 2010), lo que le permitió contar con la mano de obra para sus actividades agrícolas, ganaderas y mineras. No pocas veces utilizó los litigios como estrategia para acrecentar el patrimonio familiar, como trató de hacer en el litigio que analizaremos.

Respecto de Cristóbal Barba apenas conocemos algunas pinceladas de su vida como que fue encomendero y vecino de La Plata y, a diferencia de la red de vascongados de Ortiz de Zárate, miembro de una red de menor peso en la sociedad charqueña y de procedencia andaluza. A pesar de haberse casado con la sobrina de Juan Albertos, conocido comerciante de productos americanos y bienes suntuarios europeos y con intereses en Lima y Charcas (Presta 2000), hacia 1573 el oidor Juan de Matienzo escribió al rey solicitando ayuda para él por encontrarse en una situación de gran pobreza (Leviller 1922: 483). A comienzos de 1549 Gasca le encomendó varios grupos de moyos moyos que habían formado parte de las encomiendas que previamente Pizarro había encomendado en Alonso de Manjarrez y posteriormente en Sancho Hernandez de Ynostroza. También recibió en 1540 por encomienda de Pizarro "los indios que tuvo en la provincia de los Charcas Hernando del Castillo" (AGI. Justicia 1125: p. 101). Parte de los moyos moyos habían residido en los valles de Tarija pero cuando les fueron encomendados, lo hacían en Copavilque, en los valles cercanos a La Plata (pueblo que luego de las reducciones toledanas sería renombrado como Villaverde de la Fuente). Los moyos moyos, en escaso número, habían migrado desde el norte oriental y eran mano de obra útil en la construcción y trabajos agrícolas para encomenderos de escaso fuste que los recogieron y asentaron en sus chacras tanto en los valles chuquisaqueños como en Tarija. (Oliveto 2010; 2011)

Resumiendo: a Ortiz de Zárate se le habían encomendado carangas, chichas, juríes y tomatas mientras que Cristóbal Barba había recibido moyos moyos. Si bien ambos contendientes fueron beneficiados con repartimientos de indios, el de Barba era de menor envergadura. El desigual capital económico, político y simbólico entre los contendientes se expresa, como veremos, en los vaivenes del juicio. La controversia debía resolverse determinando si los caciques en disputa, nombrados Tusibe y Pocotas, pertenecían a una $u$ otra encomienda. En el expediente se registran 62 declaraciones emanadas de 54 testigos (algunos testificaron más de una vez). De ellos, 19 fueron indígenas que realizaron 23 deposiciones. $\mathrm{La}$ mayoría de los testimonios se brindaron en 1551, dando la singular oportunidad de captar elementos de los primeros contactos y de las reacciones de los indígenas ante esos otros culturales que fueron los europeos, así como de la construcción del nuevo mundo colonial. La originalidad de esta propuesta consiste en presentar testimonios de indígenas no cristianizados ni hispanizados. Ellos fueron citados por oficiales reales y convocados de parte de españoles en una disputa en lo civil, cuyo centro era un juicio entre españoles por la posesión de algunos de los propios testigos. En este sentido, este artículo resulta un aporte original en relación con líneas historiográficas abocadas a estudiar la participación de los indígenas como testigos en instancias judiciales, notariales o actos sacramentales, cuyos impulsores eran ellos mismos, es decir, cuando los nativos americanos comenzaron a participar en la justicia para defender sus intereses. De acuerdo con el relevamiento realizado por Caroline Cunill (2017: 18-21), los estudios de antecedentes que consideraron a los testigos indígenas los analizaron como tales en testamentos o matrimonios indígenas; también se analizaron los testigos indígenas en juicios por curacazgos y en probanzas de méritos y servicios de autoridades indígenas. Otros estudios indagaron en testimonios en juicios iniciados en defensa de sus intereses colectivos (solicitud de 
retasas). Por último, se estudiaron como testigos en juicios inquisitoriales. En cambio aquí la participación de los indígenas obedeció a la necesidad de los encomenderos de construir las pruebas para zanjar su disputa y para ello se ponía en juego la determinación de la etnicidad de los indígenas, asunto central en los testimonios que brindaron.

El litigio comenzó cuando aún no se había establecido la Real Audiencia de Charcas, donde ambos encomenderos ejercían vecindad, por lo que la primera apelación se realizó en la Audiencia de los Reyes. Los comienzos de la disputa se enmarcan en el nuevo reparto de indígenas realizado por Gasca a partir de 1548 con la partición de encomiendas pizarristas para satisfacer a los que habían sostenido la causa real durante la rebelión de Gonzalo Pizarro (1544-1548). Ello generó conflictos entre los sedientos beneficiados, que se montaron en la opacidad y contradicción de las mercedes para realizar reclamos e intentar disponer de más encomendados. Así, el centro mismo de la disputa en el juicio entre Barba y Ortiz de Zárate era la posibilidad de obtener mayor cantidad de mano de obra indígena. La discrepancia se daba en torno a unos 40 indígenas (Angelis 1998: 533). Lo magro de la cifra evidencia la magnitud de la necesidad y el contexto de escasez de la mano de obra en un espacio de frontera abierto a la explotación agrícola y ganadera. Si los inicios del pleito ocurrieron finalizada la pacificación del Perú, su conclusión coincidió con los albores de la organización virreinal motorizada por el virrey don Francisco de Toledo (1569-1581).

Las circunstancias tempranas se traducen en que la mayoría de los testigos indígenas se identificaron con nombres nativos (ver tabla 1), lo que ilustra que aún no estaban bautizados. De las 23 declaraciones existentes, hubo 16 testigos indígenas entre 1549 y 1551, de estos, cuatro tenían nombre español. En cambio, en 1566 los tres testigos tenían nombre y apellido en castellano, con lo que observamos que la evangelización estaba en marcha, ello coincide con el juramento de decir verdad que se exigía antes de cada declaración. En 1566 juraron ante la cruz, "en forma de derecho" (AGI. Justicia 1125: p. 52.). En cambio, los restantes declarantes lo habían hecho bajo fórmulas como "habiendo prometido en su ley decir verdad" (AGI. Justicia 1125: p. 75). A partir de los testimonios, se colige que ninguno de los testigos hablaba castellano. Frente a esto adquirieron relevancia los intérpretes indígenas, actores decisivos, aunque invisibles, en las prácticas cotidianas de las justicias americanas (Cunill 2019). Identificamos tres intérpretes indígenas o "indios lengua" de los que se dice que eran ladinos y cristianos. Ellos eran: Domingo (algunas veces identificado con el apellido Mendoça y una ocasión citado como testigo (ver tabla 1), Martín y Andrés quienes solo figuran con su nombre de bautismo. En el siglo XVI, ladinos eran quienes conocían las costumbres hispanas y hablaban el castellano aunque no fuera su primera lengua y por ello podían oficiar de traductores. El término lengua parece haberse impuesto en lo cotidiano para dar cuenta de estos mediadores que bien podían ser indígenas o mestizos (Jurado 2010: 286). Domingo, Martín y Andrés seguramente cumplieron la función de intermediarios lingüísticos de manera informal, ya que no fue sino hasta 1563 que la Corona emitió una ordenanza para las audiencias americanas en la que impulsó el nombramiento de intérpretes formados, quienes percibían salario. El señalamiento de que eran cristianos era fundamental pues, dentro de los cánones de la cultura jurídica católica, garantizaba la verdad y otorgaba validez a los oficios y a las declaraciones (Jurado 2010: 295).

$\mathrm{Al}$ reconocer la presencia de los intérpretes que traducían lo que escuchaban para que el escribano lo protocolizara, surgen algunas preguntas, ¿de qué manera las mediaciones descriptas y el contexto cultural ajeno (en el que, por supuesto, no solo el idioma era diferente) pudieron modificar los dichos de los declarantes?, por las mismas razones ¿cuánto pudieron haber comprendido los testigos acerca de lo que se les preguntaba? En relación con los intérpretes, como ha planteado Jurado (2010: 297), ¿acaso la traducción era inequívoca?, ¿de qué modos influirían en las declaraciones incorporadas en los expedientes las complicidades, negociaciones o enfrentamientos entre intérprete e interpretado o las partes?, ¿qué distorsiones o vacíos pudieron existir entre la palabra dicha, luego traducida, y posteriormente escrita? Aun considerando estas características propias de la práctica forense, que configuraron un proceso de violencia cultural, vale la pena analizar los testimonios de los testigos indígenas a los que en el juicio entre Barba y Ortiz de Zárate se les preguntó "¿de qué nación son?" (AGI. Justicia 1125: p. 130). Pregunta sencilla en su formulación pero cuyas respuestas, por parte de testigos tanto españoles como indígenas, no fueron tan claras. Es por eso que la riqueza de este expediente no radica en la posibilidad de conocer 
"la verdadera adscripción étnica" de los caciques disputados sino reflexionar acerca del uso de esas clasificaciones en el contexto judicial por parte de los encomenderos, oficiales de justicia, pero también los propios indígenas.

Como clarificó Kristina Angelis (1998) en el único estudio previo del litigio, el enfrentamiento entre los peninsulares se desató cuando en 1549 Ortiz de Zárate reclamó que Tusive y Pocotas eran juríes y no moyos moyos, por tanto, formaban parte de su encomienda. Su reclamo judicial se acompañó con el acto concreto de tomar a los indígenas en cuestión y trasladarlos a las tierras donde vivía el resto de sus encomendados. Francisco de Isasaga, el alcalde ordinario de La Plata y encomendero asimismo de una porción de los altiplánicos carangas (Ana María Presta Comunicación personal 2020), colectivo del que asimismo disfrutaba Ortiz de Zárate, amparó en la posesión a Barba y otro tanto hizo el Presidente Gasca dos meses después (AGI. Justicia 1125: p. 110). Sin embargo, Ortiz de Zárate no devolvió a los indígenas y presentó ante Isasaga su cédula de encomienda y su acto de posesión frente al Licenciado Polo Ondegardo, justicia mayor de La Plata y corregidor de Potosí. Isasaga amparó a Ortiz de Zárate, cambiando la posición que antes había favorecido a Barba. Este contradijo tal posesión, al tiempo que argumentó que Ortiz de Zárate había obligado a los dos caciques a mentir y a afirmar que habían servido a Retamoso, el encomendero previo de esos juríes. Además, acusaba a Ondegardo de haber actuado movido por amistad con Ortiz de Zárate y por odio y mala voluntad hacia su persona, en razón de un conflicto entre ambos en el contexto de la rebelión de Gonzalo Pizarro. Apelando así a argumentos relativos a la imparcialidad del juez movida por odios hacia uno y un vínculo de amistad con el otro.

En 1550, la Audiencia de los Reyes le indicó al juez de residencia en La Plata y corregidor Pablo de Meneses que verificara los derechos de los litigantes. Además, estableció que, hasta tanto se resolviera el conflicto, los indígenas se depositaran en un tercero (un tal Pedro Núñez de Almaraz). En los meses siguientes se presentaron las pruebas de las partes (entre las que se incluyen los testimonios indígenas). En abril de 1551 se concluyó el pleito con una sentencia a favor de Cristóbal Barba (AGI. Justicia 1125: p. 407). Meneses no se expidió acerca de si los caciques eran moyos moyos o juríes sino que resolvió, a partir de una cuestión formal, invalidando parte de la prueba escrita aportada por Ortiz de Zárate, es decir, consideró inválida una cláusula de la copia de la cédula de encomienda de su antecesor. De hecho, Barba había reclamado acerca de la autenticidad de dicha cédula, denunciando que había sido adulterada. Es decir, que su estrategia de defensa no apuntó al contenido de lo que se declaró sino a una cuestión formal en relación con la prueba.

La sentencia confirmaba los derechos de Barba sobre Tusive y Pocotas, pero no dejó a Ortiz de Zárate con las manos vacías, tal vez porque era un encomendero importante perteneciente a una familia influyente. Se le adjudicaron dos principales juríes y también otro principal y sus sujetos: el cacique Maymay, en virtud de no estar sujeto a encomienda alguna, es decir, "como indio que está vaco" (Angelis 1998: 532). No obstante, Barba y el cacique Tusive se presentaron en mayo de 1551 para reclamar que el tal Maymay no era indio vaco, sino que pertenecía a la encomienda de moyos moyos de Barba, siendo subordinado a Tusive. Esta presentación expresa la voz indígena en primera persona de un denunciante que durante todo el juicio es llamado Tusive y aquí se presenta como "Don Francisco antellamado Tuxibe señor de los indios que fueron encomendados a Alonso Manjarrez ya difunto e Cristóbal Barba" (AGI. Justicia 1125: p 415), es decir, simbólicamente posicionado en un sitio más cercano a los españoles, al ser llamado don y poseer ahora un nombre en español y haber sido bautizado. Primero planteó una cuestión de contenido y luego otras dos de forma. Explicó que Maymay no estaba disponible para ser encomendado pues debía estar en su encomienda. Luego expuso que la decisión resultaba contraria a la voluntad real y su justicia, ya que nadie debía ser despojado sin antes haber sido escuchado y vencido por fuero y por derecho. Finalmente, señalaba que no correspondía juzgar por esos temas al corregidor pues quien tenía jurisdicción era el Consejo de Indias (AGI. Justicia 1125: p: 416). ¿Cómo interpretar este reclamo? Una posibilidad es incluirlo dentro de lo que mostraron Steve Stern (1986), Jacques Poloni-Simard (2006) o Yanna Yannakakis (2006; 2008) entre otros, es decir, la rapidez con la que los indígenas se apropiaron del discurso jurídico como una herramienta más en sus variadas estrategias para limitar las acciones de encomenderos, corregidores, tasadores de tributos y otros agentes del dominio colonial mediante los mecanismos institucionales vigentes. Sin embargo, la solicitud se articuló a la perfección con los intereses de Barba quien, de 
hecho, presentó el mismo día un escrito repitiendo cada una de las argumentaciones del cacique. ¿Será entonces Tusive, repentinamente llamado don Francisco un objeto en manos de la estrategia y los intereses de su encomendero? Considerando que si la demanda prosperaba el cacique también se habría beneficiado por la incorporación de otro principal y sus sujetos a su grupo, podemos postular que aquí podría haber existido un acuerdo entre encomendero y encomendado para litigar en un mismo sentido, que redundaría en beneficios para ambos. En las últimas dos décadas se ha redimensionado el estudio de la participación indígena en el sistema judicial colonial ampliando las interpretaciones iniciales a partir de la profundización del estudio interrelacionado del funcionamiento institucional del sistema, de los múltiples protagonistas que formaron parte de él y de la tratadística. De esta manera se hace compleja la interpretación de las fuentes judiciales y se reabrió el debate por las voces indígenas en el archivo colonial matizando miradas esquemáticas y proponiendo otras posibilidades en el análisis de las resistencias no violentas ante el colonialismo español en la búsqueda de lograr acotadas reformas o mejoras en la vida cotidiana de las comunidades indígenas. En ese sentido Yanna Yannakakis (2006; 2008) en sus investigaciones pertinentes a las transcripciones orales en contextos judiciales de testigos zapotecos en Oaxaca en el temprano siglo XVIII analiza sus participaciones como actuaciones orales (oral performances) que podían ser parte de estrategias micropolíticas vinculadas a macropolíticas, que no por ser difíciles de detectar en la documentación deba considerarse que no existieron. Por el contrario, ocurrían dentro del contexto altamente ritualizado que se ponía en juego en cada declaración de los testigos indígenas que llegaron a conocer muy bien cada elemento del sistema. Los indígenas asumieron en sus propias presentaciones los criterios de validez jurídica del mundo español y sus valores para fundamentar contenidos de su propia agenda desafiando el orden que los oprimía y en un delicado equilibrio entre representar a sus comunidades, cuidar de intereses personales y mantener su legitimidad ante las autoridades coloniales. Por otro lado, Santiago Muñoz Arbeláez (2015) en su estudio de los muiscas en Nueva Granada en el siglo XVI plantea, sin propiciar una mirada armoniosa o de encuentro de culturas, romper con la lógica dicotómica y binaria de interpretar la información documental solo en términos de españoles versus indígenas pues en algunos contextos judiciales existió una convergencia de intereses entre las autoridades indígenas y, en su estudios, los encomenderos. Señala que en la gestación de la sociedad colonial que analiza, si bien la participación indígena en las instituciones coloniales fue forzada y producto de la dominación, los caciques, aun con dispar suerte, lucharon en contexto judicial por negociar cuanto pudieron los términos de la sujeción en cada escenario local y utilizando los mecanismos que ofrecía el mismo sistema que los sujetaba. El autor muestra cómo los muiscas se aprovechan de las enemistades entre los encomenderos para establecer sus propias posiciones.

El pedido de don Francisco o Tusive quedó sin respuesta y el pleito continuó en apelación hasta llegar en 1565 al Consejo de Indias por gestiones de Barba, quien continuó reclamando por los caciques y su gente, que habían sido adjudicados a Ortiz de Zárate. En los años siguientes se solicitaron nuevas pruebas (en el marco de las cuales volvieron a tomarse declaraciones a indígenas) hasta que se dictó la sentencia definitiva en 1572, confirmando la de Pablo de Meneses. Adicionalmente, Barba recibió otros cuatro principales de menor rango, siempre con sus sujetos. Ortiz de Zárate también obtuvo dos caciques y un principal. La sentencia del Consejo habría equilibrado los reclamos de ambos litigantes (Angelis 1998: 533).

\section{"Escuchando" la voz indígena en primera persona}

Para alcanzar la verdad procesal por medio de las pruebas, los jueces debían velar por el cumplimiento de ciertos procedimientos que otorgaran validez a los testimonios. En la cultura jurídica del siglo $\mathrm{XVI}$, las pruebas orales eran tan válidas como las pruebas escritas ("escrituras"), como las copias de cédulas de encomienda o de las tomas de posesión. Las pruebas orales se incorporaban a los expedientes como documentos escritos a pesar de que debían presentarse oralmente ante el notario e intérprete, si fuera necesario. Esa forma de prueba fue habitual en el siglo XVI en todas las instancias procesales, criminales, civiles o eclesiásticas (Honores 2007). Algunas de las declaraciones de testigos españoles e indígenas que incluye el juicio fueron convocadas de oficio por el juez que llevaba la investigación en cada instancia y otras aportadas por las partes. Para que pudieran ser consideradas, las probanzas 
debían presentarse en los plazos establecidos y los testigos debían cumplir varios procedimientos como prestar juramento ante Dios y manifestar que dirían la verdad y serían imparciales, es decir, que no eran movidos por odio, interés o amistad hacia ninguna de las partes. También debían declarar su edad, origen y condición para que el juez pudiera confirmar que fueran testigos hábiles o idóneos, lo que se determinaba por las mencionadas características (Cunill 2017: 10). La preocupación por regular el uso de las probanzas de testigos en las causas judiciales se materializó en la producción de tratadistas dedicados a la materia procesal y notarial que debatieron estas cuestiones entre el siglo XVI y XVIII. Como se verifica en los tratados de Gabriel de Monterroso y Alvarado (1566), Alonso de Villadiego Vascuñana (1612) o Juan de Hevia Bolaños (1797) que cita Renzo Honores (2007), existió una preocupación por determinar la validez de estas pruebas de testigos así como por definir el procedimiento para la toma de testimonios, por establecer el peso probatorio que tendrían de acuerdo con la calidad del declarante, elemento nodal a la hora de superar los casos de contradicción entre las declaraciones. Congruente con una sociedad estamental que se veía a sí misma como compuesta por personas naturalmente desiguales de acuerdo con el colectivo de pertenencia, valían más las declaraciones de los hidalgos u hombres de bien y fama que las del resto. La desigual consideración de los testigos no solo se establecía en razón de su pertenencia estamental sino también en relación con su edad y al vínculo personal y de dependencia con los declarantes, lo que se pone de manifiesto en las tachas a los testigos de partes. Para plantear la nulidad de los testimonios presentados por Ortiz de Zárate, Barba señaló que todos los testigos de la otra parte eran parientes o criados (AGI. Justicia 1125: p. 339). Respecto de los testimonios de los indígenas, dijo que eran indios de su encomienda o que había declarado a cambio de coca (AGI. Justicia 1125: p. 341), sacando a relucir un prejuicio muy común convertido en argumento acerca de lo poco fiable que resultaban los testimonios de indígenas a causa de su propensión a perjurar, mentir y ser sobornados. Por su parte Ortiz de Zárate denunció que uno de los testigos de Barba había sido condenado en otro juicio por falso testimonio (AGI. Justicia 1125: p. 353).

¿Cómo se consideraron los testigos indígenas en este contexto? En primer lugar la condición legal de la población indígena, enmarcada en el derecho natural, era la de hombres libres. Claro que esa libertad en una sociedad estamental como la del Antiguo Régimen no significaba igualdad sino que cada quien tenía derechos y obligaciones dentro del estamento o estado del que formaba parte. Aun con estas salvedades, los indígenas fueron reconocidos como testigos para la construcción de pruebas (orales y escritas) desde tiempos temprano coloniales, más allá de los reparos por su condición, y fueron elementos claves en la mayoría de las acciones legales emprendidas en la América colonial (Cunill 2017). Otro elemento a considerar por los jueces era si las declaraciones relataban hechos sabidos (tenían mayor peso) o hechos creídos. Del mismo modo, lo visto pesaba más que lo referido por terceros, por ello era frecuente que las partes descalificaran las declaraciones de testigos bajo el argumento de que "depone de oídas" (AGI. Justicia 1125: p.340). Inversamente se reforzaban relatos al decir que alguien "ha visto que" (AGI. Justicia 1125: p. 216), formato que también se halla en la confección de las preguntas a los testigos a quienes se les consulta "si ha visto que" (AGI. Justicia 1125: p. 46). También se estableció un mecanismo cuantitativo que ayudaba a alcanzar la verdad procesal (es decir, una verdad relativa a las pruebas presentadas). En la cultura jurídica del antiguo régimen se entendía que una mayor cantidad de declaraciones coincidentes conformaban un criterio de verdad. Lo cuantitativo se combinaba con la calidad del declarante, así la Audiencia de Lima acordó en 1563 que el valor probatorio de las declaraciones de dos varones o de tres mujeres indígenas era equivalente al de un español (Honores 2007). Estas apreciaciones no pretenden afirmar que en los jueces primara un criterio cuantitativo a la hora de dirimir los conflictos legales. Más bien se señalan para contextualizar debidamente el pleito, ya que esas cuestiones se verifican en el lenguaje jurídico altamente formalizado y repetitivo en las fórmulas de las presentaciones judiciales.

En el pleito encontramos 62 declaraciones de 54 testigos, todos hombres, de estos, 19 eran indígenas. En general, para los pleiteantes era relativamente fácil conseguir este material probatorio al recurrir a sus redes de amigos, allegados, subordinados y clientes. Es decir, que quien tuviera una red más amplia y con más personas de mayor calidad, de acuerdo con los criterios de la época, estaría mejor pertrechado para enfrentar un juicio. En relación con el caso que nos ocupa, la red a la que podía 
recurrir Ortiz de Zárate era más amplia y de mayor peso social que la de Barba.

En relación con las declaraciones de los testigos indígenas, tanto de oficio como de parte, se les preguntó, incluso a los propios caciques, por la "nación" y lugar de origen de Tusibe y Pocotas. Estudios previos tendieron a sintetizar nación y origen como pertenencia étnica, lo que no resulta evidente en este caso, a pesar de presentarse la situación ideal (para quienes investigamos), ya que los propios indígenas responden a la pregunta $¿ d e$ qué nación son? La Tabla 1 sintetiza las respuestas de los testigos indígenas.

Las declaraciones resultan desconcertantes y contradictorias, sobre todo si nos acercamos a ellas con la pretensión de hallar coherencia y "verdad" sumando declaraciones coincidentes. Tomando las cuatro declaraciones que efectuara el cacique Tusive, encontramos que en 1549 dijo que "es suuire"; entre febrero y abril de 1551 contestó que "es de Paiquito"; "en Paiquito los llaman juires (...) después que vino al valle de Colpavilque se dicen moyos moyos" y que "ahora es cacique principal de los lacaxas en Colpavilque". Si incorporamos las declaraciones de Pocotas, hallamos que respondió en 1551 que "es juire y no moyos moyos (...) al presente (...) se llaman moyos moyos" y que "Tusive es el principal de los lacaxas". De estos, tres de los cinco testigos que los mencionan los consideran como moyos moyos (testimonios de don Luis, Collasauai y don Hernando Bimi). Sytocha dijo que no eran ni moyos moyos ni lacaxas sino juires; por último, el intérprete Domingo dijo que oyó decir a Tusive que no son lacaxas sino naturales suries. Don Luis calificó a Tusive como xuire, Collasauai como juire, don Hernando como xueres y como sueres o suerees lo consideraron en 1566 don Joan Quino (quien además dijo expresamente que son sueres moyos moyos e no juríes), don Luis Presso y Hernando Çayva. Podríamos continuar copiando las declaraciones de los restantes indígenas sin conseguir claridad respecto del tema. Para abonar a la confusión, anotamos que en la copia de la cédula de encomienda que Gasca le otorgara a Barba inserta en el juicio se aclara en el margen que se trata de la "La encomienda de Gasca a Cristoual Barba de los yndios que tuvo Hernando del Castillo y de los moyosmoyos que llaman juries" (AGI. Justicia 1125: 101)

Acerca de este tema, Angelis (1998:537) señaló dos puntos que compartimos a la hora de interpretar estas confusas declaraciones. Primero, la sonoridad y grafía similar entre sueres / suire / juire / xuries $\mathrm{y}$, en consecuencia, las múltiples formas en que los intérpretes pudieron haber entendido y los escribanos puesto en palabras escritas y extrañas al castellano, pero con sonidos fonéticos muy cercanos. Además, en el siglo XVI, no estaban fijadas todas las correspondencias entre valores fonéticos y grafías. Así, los sonidos sibilantes que hoy escribimos con "s" se anotaban indistintamente con "s", "j" o "x". En segundo lugar, todas las respuestas podrían ser coherentes si se considera que lo que etiquetamos como "identidad étnica" era (y es) una construcción social flexible, cambiante o simultánea, es decir, contextual o situada, al punto de cambiar la denominación de acuerdo con el espacio habitado, los actores involucrados y sus dinámicas internas. Según se desprende del juicio, Tusive y su gente habían migrado desde el este de Cochabamba (Paiquito) a Tarija primero y desde allí a las inmediaciones de $\mathrm{La}$ Plata, recalando en varios puntos intermedios durante dos décadas e interactuando, incluso fusionándose con otros grupos como resultado de la inestabilidad fronteriza provocada por la disputa territorial entre los castellanos, la desintegración de la estructura de dominación inca y el avance de los indígenas que estaban fuera del dominio del Tawantinsuyu, los chiriguanaes (Oliveto 2004, 2011). En ese marco se entendería, por ejemplo, que la sujeción de Tusive y Pocotas a autoridades locales en distintos puntos del arco fronterizo oriental pudo haber sido una estrategia utilizada por los migrantes que incluyera buscar el amparo de una autoridad política ajena quedando bajo la denominación de los habitantes del espacio ocupado. ¿Será por eso que Tusive y Pocotas así como el cacique Paucar declararon que estando en Colpavilque donde están al presente se dicen moyos moyos? (Tabla 1).

Adicionalmente un colectivo indígena podía adscribir, simultáneamente, su pertenencia a un grupo étnico y a la vez a una parcialidad, ayllu o nivel de segmentación sociopolítica, llevando nombres específicos para cada segmento, elemento que en general escapaba a la comprensión y el interés de los españoles. También hay que considerar la existencia de autoadscripciones y de denominaciones impuestas, o nombres utilizados por otros respecto de un mismo grupo. Una, alguna o todas estas situaciones podrían existir en las referencias, testimonios y preguntas insertas en este juicio. En cuanto a la identificación de los indígenas cuya posesión se habrá de definir, 
Tabla 1. Testigos indígenas (AGI. Justicia 1125)

\begin{tabular}{|c|c|c|c|}
\hline Fecha & Testigo & Declaración & Instancia en que declara \\
\hline $13 / 11 / 1549$ & Tusive & Es suuire & $\begin{array}{l}\text { De oficio, ante el alcalde de La Plata, Francisco } \\
\text { de Isasaga (AGI. Justicia 1125: p. 310.) }\end{array}$ \\
\hline $26 / 2 / 1551$ & $\begin{array}{l}\text { Enpisa, natural del valle de Tarija, } \\
\text { de un pueblo encomendado en } \\
\text { Ortiz de Zárate }\end{array}$ & Son juires & $\begin{array}{l}\text { De oficio, ante el corregidor de La Plata, } \\
\text { Pablo de Meneses (AGI. Justicia 1125: p. 217) }\end{array}$ \\
\hline $28 / 2 / 1551$ & $\begin{array}{l}\text { Don Luis y en su lengua } \\
\text { Panapoma, natural de Tarija }\end{array}$ & $\begin{array}{l}\text { Tusive es xuire y los lacaxas y mamonas } \\
\text { son todos moyos moyos }\end{array}$ & $\begin{array}{l}\text { De oficio, ante el corregidor de La Plata, } \\
\text { Pablo de Meneses (AGI. Justicia 1125: p. 221) }\end{array}$ \\
\hline $28 / 2 / 1551$ & $\begin{array}{l}\text { Collasauai, cacique orejón, mitima } \\
\text { en el valle de Tarija y natural de } \\
\text { ese valle }\end{array}$ & $\begin{array}{l}\text { Tusive es de nación juire, los juires y } \\
\text { los lacaxas y los mamonas son todos } \\
\text { moyos moyos }\end{array}$ & $\begin{array}{l}\text { De oficio, ante el corregidor de La Plata, } \\
\text { Pablo de Meneses (AGI. Justicia 1125: p. 223) }\end{array}$ \\
\hline $28 / 2 / 1551$ & $\begin{array}{l}\text { Don Francisco, cacique principal } \\
\text { de los anparaes de Sedano }\end{array}$ & Son jueres & $\begin{array}{l}\text { De oficio, ante el corregidor de La Plata, } \\
\text { Pablo de Meneses (AGI. Justicia 1125: p. 225) }\end{array}$ \\
\hline $28 / 2 / 1551$ & $\begin{array}{l}\text { Paucar, cacique de los encomen- } \\
\text { dados en Juan Sedano }\end{array}$ & $\begin{array}{l}\text { Tusive es juri. En Tarija se llaman xuires } \\
\text { (...) estando en Colpavilque se llaman } \\
\text { moyos moyos }\end{array}$ & $\begin{array}{l}\text { De oficio, ante el corregidor de La Plata, } \\
\text { Pablo de Meneses (AGI. Justicia 1125: p. 230) }\end{array}$ \\
\hline $28 / 2 / 1551$ & $\begin{array}{l}\text { Ayeloma, cacique de los chichas, } \\
\text { natural de Tarija }\end{array}$ & No define pertenencia de los caciques & $\begin{array}{l}\text { De oficio, ante el corregidor de La Plata, } \\
\text { Pablo de Meneses (AGI. Justicia 1125: p. 231) }\end{array}$ \\
\hline $28 / 2 / 1551$ & $\begin{array}{l}\text { Atao, indio natural del Cuzco, } \\
\text { yanacona }\end{array}$ & $\begin{array}{l}\text { Son de nación xuyres y no son moyos } \\
\text { moyos }\end{array}$ & $\begin{array}{l}\text { De oficio, ante el corregidor de La Plata. AGI. } \\
\text { Justicia 1125: p. } 219 \text { y } 240\end{array}$ \\
\hline $28 / 2 / 1551$ & $\begin{array}{l}\text { Asto, es quichua, no es cristiano, } \\
\text { yanacona }\end{array}$ & Son juires y no moyos moyos & $\begin{array}{l}\text { De parte de Ortiz de Zárate ante el corregidor } \\
\text { de La Plata. AGI. Justicia 1125: p. } 243 .\end{array}$ \\
\hline $14 / 2 / 1551$ & Tusive, natural de Paiquito & Es de Paiquito & $\begin{array}{l}\text { De oficio, ante el corregidor de La Plata, } \\
\text { Pablo de Meneses. AGI. Justicia 1125: p. } 246 .\end{array}$ \\
\hline $15 / 2 / 1551$ & Mayma, natural de Paiquito & Vino con Tusive & $\begin{array}{l}\text { De oficio, ante el corregidor de La Plata, } \\
\text { Pablo de Meneses. AGI. Justicia 1125: p. } 248\end{array}$ \\
\hline $18 / 2 / 1551$ & Tusive & $\begin{array}{l}\text { En Paiquito los llaman juires }(. . .) \text { des- } \\
\text { pués que vino al valle de Colpavilque } \\
\text { se dicen moyos moyos }\end{array}$ & $\begin{array}{l}\text { De oficio, ante el corregidor de La Plata, } \\
\text { Pablo de Meneses (AGI. Justicia 1125: p. 249) }\end{array}$ \\
\hline $20 / 2 / 1551$ & Pocotas, indio de Tusive & $\begin{array}{l}\text { Es juire y no moyos moyos }(\ldots) \text { al } \\
\text { presente }(\ldots) \text { se llaman moyos moyos }\end{array}$ & $\begin{array}{l}\text { De oficio, ante el corregidor de La Plata, } \\
\text { Pablo de Meneses (AGI. Justicia 1125: p. 252) }\end{array}$ \\
\hline $27 / 2 / 1551$ & $\begin{array}{l}\text { Xirotarma, natural de Esquile } \\
\text { en Tarija }\end{array}$ & Vinieron de Paiquito & $\begin{array}{l}\text { De oficio, ante el corregidor de La Plata, } \\
\text { Pablo de Meneses (AGI. Justicia 1125: p. 259) }\end{array}$ \\
\hline $5 / 3 / 1551$ & $\begin{array}{l}\text { Sytocha, principal de los enco- } \\
\text { mendados en Juan Sedano }\end{array}$ & $\begin{array}{l}\text { Eran de nación juires y no moyos moyos } \\
\text { ni lacaxas }\end{array}$ & $\begin{array}{l}\text { De parte de Ortiz de Zárate ante el corregidor } \\
\text { de La Plata (AGI. Justicia 1125: p. 263) }\end{array}$ \\
\hline $7 / 4 / 1551$ & $\begin{array}{l}\text { Tolava, churumata, cacique de } \\
\text { Diego de Villavicencio }\end{array}$ & Son juries y no son naturales de Tarija & $\begin{array}{l}\text { De oficio, ante el corregidor de La Plata, } \\
\text { Pablo de Meneses. AGI. Justicia 1125: p. } 273\end{array}$ \\
\hline $27 / 4 / 1551$ & Tusive & $\begin{array}{l}\text { Ahora es cacique principal de los lacaxas } \\
\text { en Colpavilque }\end{array}$ & $\begin{array}{l}\text { De oficio, ante el corregidor de La Plata, } \\
\text { Pablo de Meneses. AGI. Justicia 1125: p. } 402\end{array}$ \\
\hline $29 / 2 / 1551$ & Pocotas & Tusive es el principal de los lacaxas & $\begin{array}{l}\text { De oficio, ante el corregidor de La Plata, } \\
\text { Pablo de Meneses. AGI. Justicia 1125: p. } 403\end{array}$ \\
\hline $18 / 3 / 1551$ & $\begin{array}{l}\text { Don Hernando Bimi, cacique } \\
\text { de la provincia de los Chichas. } \\
\text { Encomienda de Hernando Pizarro }\end{array}$ & $\begin{array}{l}\text { Son xueres no moyos moyos porque } \\
\text { los moyos son de otra parte y llámanse } \\
\text { lacaxas }\end{array}$ & $\begin{array}{l}\text { De oficio, ante el corregidor de La Plata, } \\
\text { Pablo de Meneses. AGI. Justicia 1125: p. } 336\end{array}$ \\
\hline $15 / 10 / 1550$ & $\begin{array}{l}\text { Domingo de Mendoça, indio } \\
\text { lengua, ladino y cristiano }\end{array}$ & $\begin{array}{l}\text { Oyo decir a Tusive y los suyos que son } \\
\text { naturales suries e no lacaxas }\end{array}$ & $\begin{array}{l}\text { De parte de Ortiz de Zárate ante el corregidor } \\
\text { de La Plata, Pablo de Meneses (AGI. Justicia } \\
\text { 1125: p. 210) }\end{array}$ \\
\hline 18/10/1566 & $\begin{array}{l}\text { Don Joan Quino, cacique prin- } \\
\text { cipal de los moyos moyos de la } \\
\text { encomienda de Ortiz de Zárate }\end{array}$ & $\begin{array}{l}\text { Son de nación sueres moyomoyo e } \\
\text { no juries }\end{array}$ & $\begin{array}{l}\text { De parte de Barba en la Audiencia de Charcas, } \\
\text { AGI. Justicia 1125: p. } 47\end{array}$ \\
\hline $18 / 10 / 1566$ & $\begin{array}{l}\text { Don Luis Presso, indio principal, } \\
\text { hijo de Tusive }\end{array}$ & $\begin{array}{l}\text { Son todos indios que llaman suerees } \\
\text { moyos e que no son juries }\end{array}$ & $\begin{array}{l}\text { De parte de Barba en la Audiencia de Charcas, } \\
\text { AGI. Justicia 1125: p. } 50\end{array}$ \\
\hline $18 / 10 / 1566$ & $\begin{array}{l}\text { Hernando Çayva, principal de } \\
\text { los moyos moyos, de la misma } \\
\text { parcialidad que Tusive }\end{array}$ & $\begin{array}{l}\text { Son de nación sueres e moyos moyos e } \\
\text { que no son juries }\end{array}$ & $\begin{array}{l}\text { De parte de Barba en la Audiencia de Charcas. } \\
\text { AGI. Justicia 1125: p. } 51\end{array}$ \\
\hline
\end{tabular}


la voz "suere" pero lo mismo cabe para "lacaxas y mamonas" podría haber sido la identificación de un segmento de los moyos moyos. De hecho, Martín de Almendras, testigo presentado por Ortiz de Zárate, ante una muy dirigida pregunta acerca de si sabía que los caciques en disputa eras juries y no moyos moyos responde: "entre estos yndios moyos moyos ay munchas generaciones de indios" (AGI. Justicia 1125: p. 258. La cursiva es nuestra). Isabelle Combès (2010: 22) llamó la atención por lo errado de igualar generación con grupo étnico. Generación refiere a una parte de un todo mayor, a los sujetos de un jefe, incluso a una aldea, asentamiento o ayllu. Más aún, Martin de Tortoles Villalva presentado por Barba afirmó respecto de Tusive que: "lo tiene por moyo moyo y en tal auito le ha visto andar de una parçialidad de moyos que llaman jueres" (AGI. Justicia 1125: p. 294, la cursiva es nuestra). Esta cita ¿podría abonar la idea de que fueron cambiando de nombre según cambiaban la residencia pero mantenían su vestimenta (hábito)? Con el material disponible en este litigio resulta dificultoso confirmar alguna hipótesis, pero está claro que descartamos considerar generación o parcialidad como sinónimo inequívoco de grupo étnico. María Rostworowski (1981) explicó que la voz parcialidad fue adoptada rápidamente por los conquistadores, habida cuenta de su uso en la Península en el sentido de "una parte del todo". Según su análisis, parcialidad era una mitad sociopolítica de un señorío o curacazgo que incluía a varios ayllus. Sin embargo, señala el uso que tempranamente se dio del término como sinónimo de ayllu, dándole un sentido más restringido. Combès (2010) argumentó, en función del caso de las poblaciones indígenas que habitaron la región de Santa Cruz de la Sierra en el siglo XVI, que referenciarlas en parcialidades documentadas en términos de etnias es más lo que confunde que lo que clarifica, pues homogeneiza, bajo un etnónimo, conjuntos diversos con trayectorias históricas probablemente divergentes. Otro tanto ocurre con la idea de nación, como advirtieron José Luis Martínez (2004) y Christophe Giudicelli (2009). El discurso de las naciones distinguió, clasificó y operó de manera tan tajante y oscureciendo los matices, las yuxtaposiciones, las transformaciones a medida que fue avanzando el control directo de las poblaciones indígenas por medio del reparto de encomiendas, entre otros dispositivos coloniales de poder. A estos procesos asistimos en el estudio del litigio entre Barba y Ortiz de Zárate. A la vez, los autores remarcan la importancia de las descripciones elaboradas en estos términos que tuvieron un poder altamente perfomativo al sostener y fijar identidades que se entendieron como étnicas, por ejemplo los caciques Tusive y Pocotas, sus sujetos dependientes y sus descendientes comenzaron a ser llamados en la documentación, por lo menos hasta bien entrado el siglo XVII, como moyos moyos. $\mathrm{Al}$ mismo tiempo, el lenguaje jurídico tomó (y retroalimentó también) etiquetas y definiciones como las de generaciones, parcialidades y naciones que surgieron de las crónicas, descripciones geográficas y otros documentos administrativos. Claro que el problema que tenemos es que no sabemos en qué sentido se utilizaron esos términos en el juicio. Tal vez, el análisis de las preguntas contribuya a entender un poco más las respuestas, aunque eso no equivale a conseguir el anhelando dato de la etnicidad que quienes nos dedicamos a la investigación histórica quisiéramos obtener (nada menos) de boca de los indígenas interrogados.

$\mathrm{Al}$ analizar las preguntas, resulta sintomático que en las ocasiones en que los testigos (ver Tabla1) alegaron que Tusive y Pocotas eran sueres o juires (o cualquiera de sus variantes escritas) y además recalcaron que no eran moyos moyos, les habían preguntado exactamente eso. En el marco de la probanza de Ortiz de Zárate se les preguntó: "Si sauen (...) que Tusive y Pocotas son indios juries de nación naturales del dicho valle de Tarixa y no lacasas moyos" (AGI. Justicia 1125: p. 205). En cambio, cuando el interrogatorio formaba parte de la probanza de Barba, respondieron que eran sueres moyos moyos ante la pregunta: "Si saben que el dicho caçique Tusiue e prençipal Poquitasas (...) son de naçión sueres moyosmoios e no juries" (AGI. Justicia 1125: p. 24).

¿Qué ocurrió con las preguntas y las respuestas recogidas de oficio? El interrogante formulado a los testigos indígenas cambió, pues no incluyó una afirmación, es decir, no les pidieron que digan si son moyos moyos o digan si son juries, sino que la pregunta fue abierta: se consultó "de qué nación son". Sin embargo, se corrobora que los testigos que formaban parte de la encomienda de Ortiz de Zárate afirmaron, convenientemente, que los caciques eran "juires". No hay encomendados en Barba a los que se les haga preguntas de oficio, más allá de los dos caciques con los que existía la disputa. ¿Y qué ocurrió cuando de oficio se llamó a dichos caciques? Pues Tusive respondió en 1549 ante el 
alcalde de la Plata que era "suuere". En 1551 ante el corregidor y justicia mayor tanto Tusive como Pocotas explicaron, como se mencionó previamente, que eran "juires" donde nacieron, pero desde que residían en Colpavilque (en inmediaciones de $\mathrm{La}$ Plata) "se dicen moyos moyos" (AGI. Justicia 1125, p. 248). Por último, hay solo dos casos, como el de la consulta de oficio que se le hizo a Ayeloma, cacique de los chichas y natural de Tarija, en los que los indígenas no declararon acerca de la pertenencia étnica de los caciques por la simple razón de que no se les preguntó. Es decir, que su silencio se relaciona, también, con el formato de la pregunta.

Debido a estas consideraciones, parece poco probable utilizar este juicio como cantera de datos para la definición étnica de un pequeño grupo de indígenas en Charcas en el siglo XVI. De hecho, analizarlo desde esa clave lleva a perder la riqueza de la fuente para investigar acerca de otras cuestiones que en muy raras oportunidades hallamos plasmadas en los documentos. Como la declaración de oficio de Maymay, que cuando en 1551 Pablo de Meneses le preguntó si había conocido a Alonso Manjarrez, él declaró que no podía responder "porque antes se tapa los ojos quando beya algun cristiano" (AGI. Justicia 1125: 248). Este testimonio traduce con enorme fuerza la conmoción y, seguramente, el miedo con que vivían los indígenas en los años de la construcción del mundo colonial americano, algunas de cuyas pinceladas percibimos en este juicio.

\section{A modo de cierre}

El pleito brinda la oportunidad singular de "escuchar", aunque sea intérpretes mediante, la respuesta en primera persona que dieron una veintena de indígenas a la pregunta "¿de qué nación son?" (AGI. Justicia 1125: f. 130). Sin embargo, concluido el análisis de los testimonios, comprendemos que el potencial que tienen las voces indígenas es oscurecido por la distancia cultural y un procedimiento jurídico motivado por intereses ajenos a los indígenas, impidiendo la determinación de la pertenencia étnica de Tusive y Pocotas. Sin embargo, brinda elementos para abordar algunos aspectos de la gestación de la sociedad charqueña, tema poco frecuentemente analizado a causa de la escasez documental para ello. Pero, sobre todo, la opacidad de la fuente en relación con lo que historiográficamente se denomina cuestión étnica, invita a reconocer y desnaturalizar la propia práctica historiográfica para volver a problematizar lo que entendemos como definiciones étnicas. Esas definiciones que solemos buscar y para las que muchas veces no hay una respuesta en los términos en los que nos lo planteamos. Porque, como muchos estudios han demostrado desde hace tiempo, responder respecto de la pertenencia es entrar de lleno a la cuestión de la identidad, camino siempre resbaladizo pues se trata de un campo de significación contextual, situado y por tanto variable. Justamente el juicio pone de relieve todos estos elementos.

El análisis de este litigio, que se mantuvo activo durante dos décadas a partir de una amplia variedad de recursos jurídicos para la construcción de las pruebas, argumentaciones y denuncias de tachas características de la práctica forense en la cultura jurídica del siglo XVI, permitió ir más allá de la maraña de contradicciones por la clasificación de los caciques. Corroboramos cómo el lenguaje de la etnicidad (las generaciones, parcialidades y naciones) fue incorporado a las estrategias procesales de las partes, que utilizaron y trataron de manipular las etiquetas étnicas y a los testigos, condicionando las respuestas, incluso desde la confección misma de las preguntas. En ese sentido señalamos el particular contexto de desconocimiento del idioma, las prácticas jurídicas junto con otros muchos elementos de la cultura castellana por parte de los testigos indígenas. Proponemos que las categorías que suelen tomarse como étnicas, fueron flexibles y dependían, en buena medida, de las cambiantes condiciones que tuvieron que enfrentar los declarantes en aquellos periodos iniciales. Esa etapa se caracterizó por la violencia abierta hacia los indígenas, los enfrentamientos armados entre los españoles y las contiendas relacionadas con las posesiones de las encomiendas cuando la necesidad de contar con mano de obra de las poblaciones locales llevó a los españoles a constantes enfrentamientos en terreno judicial que llegaron, incluso, al Consejo de Indias. En este escenario complejo y vertiginoso para los indígenas, ¿qué pudo haber significado ser testigo y responder acerca de la nación de pertenencia? No lo sabemos. Lo que, sobre todo, se pone de manifiesto en el litigio son las estrategias de dos españoles (de acuerdo con mecanismos muy utilizados en la época) en su disputa por conseguir mayor cantidad de indígenas encomendados. ¿Cómo actuaron los indígenas en relación con esos intereses? El juicio 
no nos permite asegurarlo pero probablemente no haya una respuesta única y taxativa. Así como es esperable que los encomenderos hayan utilizado a los indígenas y hasta obligado a declarar en un sentido determinado, también es posible que algunas autoridades indígenas (como tal vez fuera el caso del cacique Tusive, devenido en don Francisco) hayan intentado, al menos, conseguir ciertas mejoras o ventajas dentro de un contexto muy desfavorable e irreversible.

\section{Agradecimientos}

A quienes evaluaron el artículo por sus sugerencias; a Ana María Presta por sus lecturas y generoso aporte de información; a Fernanda Molina y a Sergio Angeli por sus provechosos comentarios a la versión preliminar de este trabajo presentada en el III Workshop: "Culturas jurídicas en Hispanoamérica" (2017), en la Universidad Nacional General Sarmiento, Buenos Aires.

\section{Referencias Citadas}

Angelis, K.

1998 "Litigando sobre la nacionalidad: moyos moyos y juríes en Charcas (siglo XVI)". 50 Años de Estudios Americanistas en la Universidad de Bonn. Nuevas Contribuciones a la Arqueología, Etnohistorica, Etnolingüistica y Etnografía de las Américas. Sabine Dedenbach, Carmen Arellano, Eva König y Heiko Prümers (Comps).” Bonner Amerikanistiche Studien Vol. 30: pp. 527-540, Markt Schwaben, Bonn.

Combès, I.

2010 Diccionario Étnico. Santa Cruz la Vieja y su Entorno en el Siglo XVI. Instituto de Misionología y Editorial Itinerarios (Scripta Autochtona 4), Cochabamba.

Cunill, C.

2019 "Introducción: Los intérpretes de las lenguas indígenas, ¿actores invisibles de la justicia en América”, en Las Lenguas Indígenas en los Tribunales de América Latina: Intérpretes, Mediación y Justicia (Siglos XVI-XXI). En Cunill, C. y Glave, L. M. (Coords.), pp. 9-14. Instituto Colombiano de Antropología e Historia, Bogotá.

Cunill, C.

2017 Testigos. Diccionario Histórico de Derecho Canónico en Hispanoamérica y Filipinas, siglos XVI-XVIII (DCH). Max Planck Institute for European Legal History Research Paper Series, vol. 8. pp. 1-25. Max Planck Institute, Francfort, https://ssrn.com/abstract=3073142 o http:// dx.doi.org/10.2139/ssrn.3073142 (2 febrero 2020).

Giudicelli, C.

2009 "Encasillar la frontera. Clasificaciones coloniales y disciplinamiento del espacio en el área diaguito-calchaquí (S. XVI-XVII)". Nuevo Mundo Mundos Nuevos. http:// journals.openedition.org/nuevomundo/56802 (25 de enero de 2020).

Honores, R.

2007 "Los caciques y las pruebas: el uso de las testimoniales en las disputas por cacicazgos en la Audiencia de Lima, 1550-1560". Actas de XI Jornadas Interescuelas/ Departamento de Historia. Facultad de Filosofía y Letras, Universidad Nacional de Tucumán, Tucumán. https://www. aacademica.org/000-108/924 (10 de febrero de 2020)

Jurado, M. C.

2010 "Don Pedro de Dueñas, indio lengua. Un estudios de caso de la interpretación lingüística andino-colonial en el siglo XVII". Anuario de Estudios Bolivianos Archivísticos y Bibliográficos 16: pp. 285-309, Biblioteca y Archivos Nacionales de Bolivia, Sucre.
Leviller, R.

1922 LaAudiencia de Charcas. Correspondencia de Presidentes y Oidores. Tomo II. Imprenta de Juan Pueyo, Madrid.

Martínez Cereceda, J. L.

2004 "Cómo hablar de indios e identidades en el siglo XVI".

Historia Indígena 8: pp. 41-55. Universidad de Chile.

Facultad de Filosofía y Humanidades. Departamento de Ciencias Históricas, Santiago de Chile.

Muñoz Arbeláez, S.

2015 Costumbres en Disputa: los Muiscas y el Imperio Español en Ubaque, Siglo XVI. Universidad de Los Andes. Facultad de Ciencias Sociales. Departamento de Historia, Bogotá.

Oliveto, L.G.

2012 "Nuevas perspectivas sobre las encomiendas de indios de los valles orientales de Tarija". Surandino Monográfico Vol. 2, $\mathrm{N}^{\circ}$ 4, http://revistascientificas.filo. uba.ar/index.php/surandino/article/view/5913 (18 de enero de 2020).

Oliveto, L. G.

2011 "De mitmaqkuna incaicos en Tarija a reducidos en La Plata. Tras las huellas de los moyos moyos y su derrotero colonial". Anuario de Estudios Bolivianos Archivísticos y Bibliográficos 17: pp. 463-490, Biblioteca y Archivos Nacionales de Bolivia, Sucre.

Oliveto, L. G.

2004 "Caminantes de sierra y selva. Identidad y frontera en el siglo XVI". Tesis de licenciatura inédita, Universidad de Buenos Aires. Facultad de Filosofía y Letras, Buenos Aires.

Oliveto, L. G. y Zagalsky, P.

2010 "De nominaciones y estereotipos: los chiriguanos y los moyos moyos, dos casos de la frontera oriental de Charcas en el siglo XVI". Bibliographica Americana 6, Biblioteca Nacional Argentina, Buenos Aires. https://www.bn.gov.ar/ micrositios/admin_assets/issues/files/390e2aea7a7f468d0 211fd3bcd034e76.pdf (16 de enero de 2020).

Poloni-Simard, J.

2006 El Mosaico Indígena. Movilidad, Estratificación Social y Mestizaje en el Corregimiento de Cuenca (Ecuador) del Siglo XVI al XVIII. ABYA YALA, Quito.

Presta, A. M.

2000 Encomienda, Familia y Negocios en Charcas Colonial (Bolivia): los Encomenderos de la Plata, 1550-1660. Instituto de Estudios Peruanos, Lima. 
Rostworowski de Diez Canseco, M.

1981 "La voz parcialidad en su contexto en los siglos XVI y

XVII". Etnohistoria y Antropología Andina. Amalia Castelli, Marcia Koth de Paredes y Mariana Mould de Pease (Comps.), Stern, S. pp. 35-45. Centro de Proyección Cristiana, Lima.

1986 Los pueblos indígenas del Perú y la conquista española. Huamanga hasta 1640. Alianza Editorial, Madrid.
Yannakakis, Y.

2008 "Witnesses, spatial practices, and a land dispute in colonial Oaxaca". The Americas 65:2, pp. 161-192.

Yannakakis, Y.

2006 "Hablar para distintos públicos: testigos zapotecos y resistencia a la reforma parroquial en Oaxaca en el siglo XVIII". Historia Mexicana, vol. LV, núm. 3, pp. 833-893.

\section{Notas}

1 Archivo General de Indias. Justicia 1125. N ${ }^{\circ}$ 5, R.1, El capitán Cristóbal Barba, con el adelantado Juan Ortiz de Zárate, ambos vecinos de la ciudad de La Plata, sobre el derecho a los indios moyos. Dos piezas, 1551-1572. En adelante AGI. Justicia 1125. Utilizo la versión inédita y paleografiada que me facilitara generosamente Catherine Julien. No hay foliación original. Existe foliación agregada en el documento pero es inconsistente por eso utilizo la numeración de páginas agregada por Julien.

2 Entre ellos se cuenta a Juan Ortiz de Zárate, de los primeros en ocupar los valles de Tarija (en la frontera suroriental) y, más tarde, en el Río de la Plata, jurisdicción para la que fue nombrado adelantado para refundar Buenos Aires. También encontramos a Juan de Garay, sobrino de Ortiz de Zárate y responsable de la segunda y definitiva fundación de Buenos Aires en 1580. Asimismo, comparecen en el juicio destacados vecinos de La Plata como los hermanos encomenderos de Tarabuco, Martín y Diego de Almendras.
Ellos consolidaron un prominente linaje que había iniciado su tío Francisco de Almendras, paisano y fiel capitán del rebelde Gonzalo Pizarro. De esa misma red de familiares y allegados formaron parte otros apuntados en el juicio, como Martín Monje, cuñado de los Almendra o Martín de Tortoles Villalva casado con una prima de los Almendra (Presta 2000), ambos encomenderos de La Plata. Los negocios, los vínculos familiares y las lealtades existentes entre el clan de los Almendras y el de Ortiz de Zárate se hacen patentes a lo largo del pleito. Incluso aparece en tres oportunidades Andrés Manso como firmante y testigo de diferentes actuaciones, quien cinco años después sería expedicionario al oriente charqueño, fundador de la villa de Santo Domingo de la Nueva Rioja (también llamada Condorillo), nombrado gobernador de la provincia de los chiriguanaes en un espacio que se conoció, justamente, como "los llanos de Manso", anticipando la expansión colonial a Santa Cruz de la Sierra. 